\title{
The Birth of Disability
}

Rod Michalko

Camrose Lutheran College

\section{Familial Conceptions of Good and Bad Births}

Parents typically anticipate and approach the birth of a child with a particular set of conceptions regarding birth and children. This set of conceptions generally focuses on parental and familial expectations of how the child will influence the life of the family and how, in turn, the life of the family will influence the child.

These conceptions and expectations are derivatives of societal and cultural ideas about the family. This is to say that a culture provides its members with ways of thinking about, speaking about, and acting toward the event of birth. Thus parents anticipate and approach the birth of a child within the framework of a set of conceptions and expectations derived from culturally available ways of understanding the birth of an offspring.

Conceptions of birth typically presuppose "good health" as a standard for a "good birth."

Parents awaiting the birth of their child naturally assume that their baby will be healthy, handsome, and wise, and have a winning personality.... As soon as the baby is born they seek immediate reassurance that their new son or daughter is "normal" and at their first opportunity new mothers fondly check to see if the baby has the regular complement of fingers and toes. (Scott, Jan, \& Freeman, 1977, p. 5)

Here we have an understanding of a birth as good insofar as the result or product of the activity of giving birth is good, that is, whether a birth is a good birth is judged on the basis of its outcome. The worthiness of the travail of birth itself is judged on the basis of its product. In this sense, judging a birth relies on an examination not of travail (work), but instead the judging of a birth relies on the examination of what the birth intends, its end, its product. In Scott, Jan, and Freeman's terms, the product of the activity of birth is not merely a baby, but is a baby who is healthy, normal, and is a baby who has the regular complement of fingers and toes. Thus if the baby is healthy, normal, handsome, wise, has all his fingers and toes, and has a winning personality, the birth is judged to be good.

Scott, Jan, and Freeman tell us that parents naturally assume that the birth of their child will be a good birth. In fact, "they [parents] do not let themselves even think about the possibility that something might be wrong with the baby" (p. 5). In this formulation, a natural attitude with which to anticipate a birth is to assume the 
goodness of birth and, in particular, to assume that a particular birth will be good insofar as that particular birth will naturally yield the outcome of a healthy, normal offspring. In contrast, this paper is interested in the work which parents do to "normalize" the anxiety about the health of the baby. This anxiety, and the parents' work of coming to terms with it, can be said to be the first act of parental responsibility in decision making. The first ambition which parents may have for their child, prior to being able to concretely care for it, is that the child be "adequate," that is, normal and typical.

In the interview which follows, a mother dismisses the need for anxiety about her in utero child by equating the typical normalcy of the pregnancy with the typicality of the child to be.

I think the only thing, um, this friend of mine that I worked with, um, was pregnant at the same time and she had a lot of trouble in her pregnancy. She was constantly bleeding and constantly having pains, and all this kind of stuff.

And you weren't?

And I wasn't and I was, you now, I'm thankful I'm healthy and not having a bad time and I was always saying to her, well, you know, I hope, um, that your baby's okay when it comes out and I never thought to myself that my baby wouldn't be because I had no problems at all.

Did you ever think that?

Well, it sort of goes through your mind, you know.

120 I, I don't think you can plan for something if you don't know it's going to happen. Like we had absolutely no idea and the doctors had absolutely no idea and you can't, like, you can't live in fear that something's going to be wrong.

Well, I was little anxious but I don't think it was because I thought there was anything wrong with her. I think it was just wanting to get rid of this pregnancy. I'd been pregnant for $9 \frac{1 / 2}{2}$ months and I'd had enough, um.

The mother in the first exchange gave birth to a visually handicapped child. Because she was "healthy and not having a bad time" (in her pregnancy) she was not concerned about the health of her child; in other words, she was not concerned that the outcome of her pregnancy would be anything but a healthy, normal child.

She had been seeing her doctor regularly during her pregnancy.

We saw him once a month up until the seventh month and then we saw him twice a month and then the last three, the last three weeks, we saw him once a week.

One of the results of these medical visits was that the doctor did not anticipate any problem with the pending birth. "Like he had absolutely no idea that there was anything going to be wrong."

The anticipation and assumption of a problematic birth, then, requires some evidence, or more correctly, requires a sign. For this 
mother, there was no sign of problems. Unlike her friend who was "constantly bleeding and constantly having pains," this mother was "healthy and not having a bad time." The signs were not present and so she did not have a reason to expect that her child would be unhealthy or abnormal.

This mother interpreted "bleeding" and "pain" as signs of problems. In fact, she was "always" saying to her friend "I hope, um, that your baby's okay when it comes out." In other words, these signs (bleeding and pain) were understood by her, and presumably by her friend, as reasons to expect problems at birth and as grounds for extending encouragement. Moreover, this mother evoked these signs as occasion to extend hope to her friend-hope that these signs would only point to trouble and not turn out to be prophetic.

At the same time, she said that she "never thought to myself that my baby wouldn't be because I had no problems at all." By "my baby wouldn't be," she means that she never thought her baby would be unhealthy or abnormal because the signs for ill health and abnormality were not present.

This mother was not alone in her anticipation and assumption of a good birth. Her doctor had "absolutely no idea that there was going to be anything wrong." In other words, given the regularity of appointments and given that her doctor did not anticipate any trouble during the birth, her anticipation and assumption of a good birth was legitimated and justified. In this instance, the legitimization and justification of a good birth did not come from any external source but from the external source of medicine as represented by her obstetrician. The mother's own perception of her good health and problem-free pregnancy, together with medicine's anticipation of a good birth, permitted her to anticipate nothing short of a good birth. Medicine is, after all, typically understood as a legitimate, if not reliable, judge of health and medicine's assumption and anticipation of a good birth is thus typically taken seriously.

In this sense, medicine can be conceived of as the quintessential reader of signs. That is, medicine can read the signs that point toward a bad birth. More than this, medicine not only reads these signs but also, unlike the lay person, recognizes that which is a sign. Thus the mother is able to recognize that "constant bleeding and pain" signify the legitimate and justifiable suspension of the anticipation of a good birth.

But the mother understands that there exist other signs of a bad birth-not only signs which she is unable to read but also signs which she is not able to recognize. Thus she makes regular visits to an obstetrician, visits that are motivated and informed by her conception of medicine as the quintessential recognizer and reader of signs. The obstetrician will not only act as the final arbiter and judge of the mother's own recognizing and reading of signs but will also act as the discoverer and reader of signs that she, by virtue of not being 
an obstetrician, was not able to discover or read herself. In other words, the obstetrician will confirm or disconfirm her own impression of a good or bad birth as well as inform her about what the signs point to in relation to a good or bad birth. The obstetrician sees not only what the mother herself sees but also sees that which she is unable to see.

As Foucault (1973) suggests, the patient has been seen by the doctor, the patient has been examined by the doctor, and thus signs of good or bad health are discovered and read, that is, signs are seen and taken into account in the ways in which medicine has of taking signs into account.

"Seeing the patient" is not, from the point of view of medicine, a common sense version of looking; anyone can see the patient. But as Parsons (1951, pp. 439-447) has suggested, patient is not merely a category that describes an individual's state of health. Rather than being a descriptive category, it is a social category insofar as patient requires particular social relations to institutions and traditions such as medicine. Patient relies on socially organized versions of good health and ill health-versions that are organized socially within a cultural framework. This is to say that there are culturally available ways of thinking, speaking, and acting that socially accomplish good and ill health. Conceived socially, health is interpreted on the basis of certain segments of culture, medicine for the most part, and thus the tradition of medicine is evoked, often tacitly, as part of the interpretive work that yields the recognition of good or ill health.

Patient, then, is a social status and although anyone can see the patient, not anyone can see the patient in relation to the patient's status as social. For to see an individual as patient already requires placing the individual within the interpretive framework of the tradition of medicine. Further, although anyone can see an individual as patient (see the patient) by locating the person within the interpretive framework of the medical tradition, the claim that the "patient has been seen" cannot legitimately be made by anyone. This claim can be made only by one who represents the medical tradition, that is, by one who in his or her seeing, represents the medical version of seeing.

In this sense, seeing the patient requires, as Foucault puts it, a medical gaze which is not the "gaze of any observer, but that of a doctor endowed with the power of decision and intervention" (1973, p. 89). The medical gaze is not a gaze "content to observe what was self-evident: it must make it possible to outline chances and risks; it was calculating" (p. 89).

When the mother said that her obstetrician had "absolutely no idea that there was going to be anything wrong," she was saying that she (the patient) was seen by the doctor. This seeing (the medical gaze) saw no signs of trouble; the gaze did not result in the anticipation of 
a bad birth. This is not to say that the medical gaze-reflected in the mother's appointments with her obstetrician-did not result in any signs, for indeed it did. The signs that were recognized and read by the obstetrician were signs that pointed to a problem-free birth; they were the signs of a good birth. The mother's own perception of herself and her pregnancy, namely, "healthy and not having a bad time" together with "having been seen" by her obstetrician, signified a good birth.

This is not to suggest that even though the signs of a bad birth are not present, the possibility of a bad birth is not considered. In fact, this mother's husband said that the possibility of a bad birth "sort of goes through your mind." But, as she says, "you can't live in fear that something's going to be wrong." Presumably, "living in fear" would be justified only with the presence of signs for a bad birth.

Thus these parents had no reason to anticipate a bad birth. Despite this, the outcome of the birth is the final arbiter of whether the birth is a good birth. Again, the parents will count the fingers and toes of their newborn and the obstetrician will conduct his examination. These two aspects will combine to proclaim mother and newborn either in good or ill health. Thus the outcome of the birth, that is, the child, and the subsequent examination, determine whether a birth is good or bad. Before the event of birth occurs, however, final judgment on whether the birth is good or not is suspended. The degree of anxiety over this suspension, however, is to a large extent determined by whether signs are present that point toward a bad birth. Even though she was two weeks overdue, the mother was only "a little anxious" and because the signs of a bad birth were not present, she was tired of "just waiting" and wanted to "get rid of this pregnancy."

\section{The Injustice of the "Bad" Birth}

Again, even though the signs of a bad birth are not present, bad births can and do occur. Signs are, after all, just that-signs. And, signs point the way, they are not the way; signs point to an occurrence, they are not the occurrence. This is how the following parents speak about the bad birth of their child - a birth that was bad even though the corresponding signs were not present and even though the only signs that were present were the signs of a good birth.

I would sit there, like, "why us?" We got married before we had children which nowadays they don't, like, we got married, we waited four and a half years to have a child, we wanted to, you know, get settled, get a house, 'cause I didn't want to raise a child in an apartment. We waited, we bought him nice furniture ... you know, so we could spoil the s--- out of him. Everything had to be perfect.

So you were really looking forward to this baby.

Yeah. 
Oh yeah.

And then, all of sudden, bang-oh. You get a visually impaired child and you sit back and "why us?" Look at all these girls who go out and on the first time they do it, they get a kid that they don't even really want.

Sometimes you hear about girls ... like I know some girls who get pregnant and have babies and drank through their whole pregnancy and they smoked and they were out partying until, you know, whatever time in the morning, and they had healthy kids! That's what I thought sometimes. I never did any of that.

Was there any guilt involved in this, like, it seems that all the things you're kind of pointing to, like explicating or sort of like, well, I fixed the room up and maybe if I'd been lazy about that, maybe I would have deserved this. Sounds like it's guilt related...

No.

No, we didn't feel guilty.

No? You don't feel like it was?

Not only were the signs of a bad birth not present, but they had prepared for the birth of their child. The notion of preparation raises the possibility of making a difference to whether the birth is good or bad.

These parents did what they could to ensure the fulfillment of their desire for a good birth. Unlike some other "girls" who get pregnant, the mother did not smoke or drink throughout her pregnancy and she did not go to parties and stay out until "whatever time in the 124 morning."

The parents also prepared in other ways. They got married before they had children which "nowadays they don't." They waited four and a half years to have a child. They waited to "get settled" and they waited until they bought a house because they "didn't want to raise a child in an apartment." They decorated a room "really nice" for their expected baby and "bought him nice furniture." As the father said, "everything had to be perfect."

But everything wasn't perfect, that is, their baby was visually impaired. What was perfect, then, was the parents' preparation as well as the precautions they took to ensure a good birth. Perfection, then, refers to the state of preparation for the child they were expecting. Certain precautions such as not smoking and not drinking during the pregnancy were taken, and certain preparations such as decorating and furnishing a room were made for the expected arrival of the child.

The preparations included an ethical sense of marriage and family. The parents acted in what were, for them, ethical ways. Their version of ethics in relation to marriage and family focused on timing. The mother became pregnant only after they were married and only after they were prepared to raise a child in a house rather than in an apartment. Thus for them, a good marriage would not be motivated by a premarital pregnancy, and the good upbringing of a child could not be undertaken in an apartment but required a house. In 
this sense, the parents did all the "right things." Despite the "rightness" of their activity, however, the birth of their child was not a good birth insofar as their child was visually impaired.

Given the birth of a visually impaired child, the interviewer raised the question of guilt. Both parents emphatically denied any guilt feelings for producing a child with a visual handicap. Even though the interviewer expressed surprise at this emphatic denial of guilt, "No? You don't feel it was?" it is not surprising that the parents did not experience guilt.

The father says that there are "girls who go out and on the first time they do it, they get a kid that they don't even really want." The mother says that there are "girls" who smoke, drink, and party throughout their pregnancy "and they had healthy kids!" What's more, the mother "never did any of that" and had an unhealthy child.

These parents do not feel guilty about producing a visually impaired child. The fact that they conceived a visually impaired child was none of their doing or not doing. In fact, a visually impaired child, a bad birth, is not deserved and is not deserved especially by those who take precautions and prepare. When "everything is perfect" a bad birth is not deserved, that is, a bad birth is not just.

In this way, the parents are not experiencing guilt, but instead are experiencing injustice. They behaved ethically in their preparation and in their precaution and, in this sense, behaved justly. Their ethics are grounded in convention. The mother became pregnant after marriage, she did not drink, smoke, or party during her pregnancy, she did not become pregnant until she and her husband were settled, bought a house, decorated and furnished a room for their expected child, in short, she did not become pregnant until "everything was perfect." The parents behaved conventionally and, for them, conventional behavior is ethical and just behavior.

Convention disappointed the parents insofar as the ethics and justice of convention which resulted in "everything being perfect" did not result in a good birth. That is, the perfection of convention yielded imperfection. The parents' sense of perfection, that is, their sense of ethics and justice, is grounded morally in convention. Their ethical and just behavior is governed and oriented by the moral ground of convention. Their behavior and the moral ground of their behavior, however, are understood as the same thing. In other words, morality and ethics are synonymous. There is no difference between action and that which governs and orients action. It is this notion - that action and that which governs and orients action are the same-which results in these parents' experience of injustice.

These parents are not guilt ridden over the birth of their visually impaired child. Instead, they are angry at, and bitter toward, the essential injustice of convention. Convention, as moral ground, can lead 
either to justice or injustice. Because conventions change there is no way to predict whether conventional action will yield justice or injustice. In this sense, the only good thing about acting conventionally is that it is conventional action. Convention conceived of as simultaneously moral ground and ethical action results in happenstance, that is, results in the accident of a bad birth or in the accident of a good birth.

\section{The Detection of the Problem and the Identification of Abnormality}

The occurrence of a bad birth is not, in every instance, immediately recognizable. Unlike various forms of gross deformities, which is to say, immediately perceivable deformities or even death, visual impairment is a more subtle type of bad birth. Visual impairment is often not perceived by a cursory glance or examination. The detection of a visual impairment in a newborn cannot be described with the metaphor of "counting fingers and toes." In most instances, the recognition of a visual impairment requires more than a simple looking and seeing; the detection of a visual impairment in a newborn typically requires more than a simple looking and seeing. The detection of a visual impairment in a newborn typically requires the recognition and reading of signs that point to visual impairment.

Further, the occurrence of a bad birth, for example, the occurrence of a visual impairment in a newborn, requires a set of interpretive procedures. Signs must be read within particular interpretive frameworks in order that a visual impairment in a newborn can be said to have occurred. Moreover, once detected, visual impairment must be placed within an interpretive framework in order that its occurrence can be found to be sensible. Parents of a visually impaired child must, in other words, develop a version of visual impairment insofar as they must develop a version that provides for the sensibility of the impairment, that is, provides for a sense of what the impairment is and provides for a sense of what their child now is. The initial sense of visual impairment is typically provided for by the tradition of medicine. In fact, the sense of the process and phenomenon of birth itself is provided for by medicine. Given a medical version of birth, it is not surprising that the sense of a good or bad birth is also provided for by medicine. Typically, then, the problem of a visual impairment present in their newborn is initially understood by parents as a medical problem. Formulated medically, a visual impairment is understood as a condition that should have been otherwise insofar as a good birth is, in part, a birth that shows no signs of medical problem. Further, a medical version of a bad birth brings with it the grammar (requirements) of detection, description, explanation, and cure. 


\section{Consider the following:}

Okay. She was $3^{1 / 2}$ months old when we noticed that she wasn't following objects. And, I guess because she was our first child, we didn't really realize that she should have been seeing much earlier.

Nothing, nothing. Well, her eyes were jumping ...

But, you know, we thought that, well, some people had told us that that's normal so we set it aside. And we had an impression that she was looking at things. I guess what she was doing, she was just... her eyes were so close to your face when she was looking at things. And it turned out that she wasn't really. That was just an impression.

So, you did notice the eyes...

Yeah. They were jumping...

We noticed that...

...moving...

Yeah. A lot of jumping around...

... unsteady...

... flickering...

So, what did you do? Did you say ...?

No. No. Nothing at the time because, uh, I don't know... We had read about it or people had told us that it's quite normal, apparently it is, quite normal that immediately after birth a baby's eyes can, often, do jump around and do all kinds of things. Because, in fact, in retrospect, when we talked to the, our pediatrician and mentioned this, you know, this whole problem that people had said babies will often do this, he said, yes, as a matter of fact that he did notice the flickering and he wrote it off as being the same thing. Oh, yeah, that's not a serious thing. That's quite often how it happens. It goes away. Well, it didn't really go away entirely....

We started... well, actually we started suspecting that she wasn't going to walk into the room and, rather than looking over at you which by that age we thought that she should, she just kept, maybe, looking up at the ceiling or whatever, or at something else. So, then we started ...

Pediatrician, yeah. And then he referred us to a neurologist who works with the eye. He was hoping that it was another problem rather than blindness, I think.

How do you mean he was hoping that? Did he tell you that?

Well, he probably thought it was a brain problem or something. Or something that can be operated on. Something other than blindness. I guess he didn't want to frighten us.

And then, once the neurologist gave his version, then we would look into the eyesight, because he basically had told us after his examination that there is a problem.

That was our biggest shock.

This was before we went to the pediatrician. Once we noticed that she wasn't, you know when we walked into the room, like I mentioned before, didn't look at us or hand us something, the odd time, I don't know; you have something in your hand and you thought that she should be looking at it.... Anyway, when we started suspecting that there might be something then we went into her at say, nighttime, when she was lying in her crib and just took in a flashlight. And started to fool around with the flashlight and we basically got the same reaction as what the neurologist did. 
As was the case in the recognizing and reading of the signs of a bad birth, parents also recognize and read signs of a possible eye problem. These parents noticed that when their child was $3 \frac{1}{2}$ months old "she wasn't following objects." They also noticed that "her eyes were jumping" and that her eyes were "moving," "unsteady," and "flickering." But because "she was our first child, we didn't really realize that she should have been seeing much earlier." Further, they noticed that when they walked into their child's room "rather than looking over at you, which by that age we thought that she should, she just kept, maybe, looking up at the ceiling or wherever, or at something else."

Not following objects, flickering eyes, and not looking at the parents when they entered her room were all interpreted by the family as signs of a possible eye problem. But because this was their first child, they did not take these signs seriously. The idea of a "first child" metaphorically speaks to the idea of comparison. That is, the parents had no way of comparing their child's development, vis-àvis her eyes, with the development of another child whose eyes were developing normally. Moreover, they "had read about it" and people had told them "that it's quite normal, apparently it, is, quite normal that immediately after birth a baby's eyes can, often, do jump around."

128 Because of reading, hearsay, and the lack of comparison, this family read the signs as signs of normalcy and so they "set it aside." They developed an "impression that she was looking at things."

The impression of normalcy that they had developed was not a derivative of the intentional impression constructing activity of counting fingers and toes. This is to say that the parents did not examine their daughter's eyes as a way to develop an impression of normalcy in the same way that they may have counted their daughter's fingers and toes to develop the same impression. Counting fingers and toes is, in a sense, an inventory-taking activity-a kind of accounting for the presence of all of the infant's allotted parts. With the exception of taking into account the physical structure of an infant's eyes, there is no inventory-taking activity that can be intentionally performed as a way to develop an impression of whether the infant's eyes are operating properly; there is no analogous counting fingers and toes activity that will inform parents of whether their infant can see.

Instead, the parents' impression of whether their infant can see is derivable only from within the framework of an infant's typical round of everyday life. This is to say that parents interpret (develop an impression of) their infant's ability to see on the basis of their typification of infant life. What does an infant typically do? How does an infant typically respond to his or her environment? How does an infant typically act? What does an infant typically find 
interesting to look at? These questions all represent adult formulations of infant life and adult orientations to that life. From this formulation and orientation, things can be noticed, impressions can be made. In this way, disruption to these formulations and orientations are noticeable as atypical. Another way of saying this is that if the infant orients to his or her round of everyday life in a way which is different from adult orientation to their infant's round of everyday life, then adults may suspect abnormality or atypicality. Thus atypical seeing or, in other words, a visual impairment is grounded in a version of typical seeing.

In a way, the problem that these parents initially formulate is the problem of typicality, that is, what, for an infant, amounts to typical seeing? The problem of the parents, then, is the problem of typicality; their problem is the development of an image of a typical infant from which they can evaluate and judge their child's particularity and difference.

Acting within the medical version of birth, this family consulted their pediatrician about the "flickering" of their daughter's eyes. The pediatrician had also noticed these signs and provided a reading of them, that is, that "as a matter of fact . . he did notice the flickering and he wrote it off as being the same thing. Oh, yeah, that's not a serious thing. That's quite often that it happens. It goes away."

Again, this interpretation is not just any interpretation but is the interpretatation of medicine. This interpretation was not something that the parents had read somewhere or heard somewhere. Instead, it was an interpretation legitimated and justified within the tradition of medicine. Having heard somewhere and having read somewhere that babies' eyes do flicker and having this hearsay legitimated by a pediatrician, it is not surprising that they did not take the signs of an eye problem seriously.

Before the family consulted their pediatrician, however, they began a process of trying to establish whether their child was seeing in a typical way. In other words, they entered into a process of trying to interpret the signs of their daughter's eyes not following objects and flickering.

Well, I think the clincher came when we started to do our own thing like saying well, she wasn't following any light. We started to do our own experiment.

In this sense, they did take the signs of an eye problem seriously. They took them seriously enough to conduct experiments. In other words, the parents were "suspicious" that these signs did not reflect typicality. In developing their notion of what and how an infant sees, they suspected that their child was not typical. Despite their uncertainty, that is, despite the fact that they were only suspicious, 
the parents were certain that any infant's eyes (their idea of a typical infant) would follow the light of a flashlight if shone in a dark room. In this sense, the parents began the process of diagnosis. They conducted an experiment (test) as a way to determine whether their child had an eye problem. This type of "self-diagnosis" was their way to read-their way to read the signs of flickering eyes, not following objects, and so on.

Following the family's recognition of signs and subsequent reading of signs, the medical version of potentially problematic eyes expressed itself in terms of a referral to a neurologist. The parents' experiment with the flashlight increased their suspicions of the presence of an eye problem in their child and these experiments "basically got the same reaction as what the neurologist did." In a sense, then, they understood the neurologist's tests, as well as the results of these tests, to be, in principle, the same as their own "flashlight test." And the result of this testing was the verdict that their child was blind and "that was our biggest shock."

The parents said that the neurologist was "hoping that it was another problem rather than blindness." The neurologist hoped that "it was a brain problem or something. Or something that can be operated on. Something other than blindness."

The medical conception of a problem brings with it the conception of cure. In a sense, the aim of medicine, among other things, is to di130 agnose and cure problems. The idea of diagnosis is thus informed by the idea of cure. It was this diagnosis/cure, or put differently prob$\mathrm{lem} /$ solution notion of medical practice that permitted the neurologist to "hope" that the problem was neurological rather than blindness.

Certain neurological problems can be remedied-are something that can be operated on-whereas blindness is typically inoperable, irremediable. The irremediability of blindness disrupts the diagnosis/cure dichotomy. The only hope that medicine has is the hope of cure; the hope that medicine brings to the human condition is the hope of cure. Without cure, medicine brings hopelessness to the human condition. The medical gaze is oriented to, and by, the hopeful character of cure. Without cure, then, medicine need no longer gaze, need no longer "see the patient," because any further gaze would only bring more hopelessness. In this sense, the diagnosis of blindness was not only the "biggest shock" to the parents, it was also the biggest shock to the neurologist. Further medical intervention would be hopeless. The shock for medicine resides in the notion that its intervention will not make a difference insofar as the difference it does make is the difference of hopelessness. The biggest shock to medicine, then, is not only that it is no longer needed but that it (medicine) is hopeless.

Parents of a blind child must now go beyond medicine, beyond hopelessness. They must go beyond a medical formulation of 
blindness and thus beyond a medical understanding of the life of their child. The essential task of the parent-of sightedness-now becomes the task of engaging in work oriented to developing the hopeful character of their child's life-of blindness. This means that the parents and child must enter a hopeful relation; a relation that will bring blindness and sightedness into formulative conversation.

\section{Acknowledgments}

1. The research for this paper was funded by Health and Welfare Canada Grant 6606-2766.

2. A special debt of thanks is owed to the parents who were willing to talk about their experiences.

\section{References}

Foucault, M. (1973). The birth of the clinic: An archaeology of medical perception. New York: Random House.

Parsons, T. (1951). The social system. New York: Free Press.

Scott, E.P., Jan, J.E., \& Freeman, R.D. (1977). Can't your child see? Baltimore: University Park Press. 